\title{
Structure and properties of nanocrystalline chitosan
}

\begin{abstract}
Chitosan and its derivatives are polymers with excellent properties to be used in regenerative medicine because they guarantee efficiency in the healing process. This polymer has a great potential for the development of a new generation of biomaterials that can be used in regenerative medicine and tissue engineering. The nanocrystalline chitosan $(\mathrm{nCh})$ is a modified form of chitosan prepared by the method of obtaining chitosan salts. It is characterized by having the same special properties of the precursor chitosan as biocompatibility, bioactivity, be non-toxic and biodegradable. The aim of this study was to develop a new method of obtaining nanocrystalline chitosan according to their chemical and physical characterization. The material was characterized by Absorption Spectroscopy in the Infrared Region-with the Fourier transform (FTIR-ATR), scanning electron microscopy, SEM, Nuclear Magnetic Resonance, NMR, Diffraction of X-rays, particle size analysis and the potential Zeta. The results indicated that the process of obtaining nanocrystalline chitosan did not change the structure of the precursor chitosan. The analysis in the FTIR showed the same functional groups of the precursor chitosan. The $1 \mathrm{H}-\mathrm{NMR}$ spectroscopy was helpful in the analysis of the chitosan samples in a wide range of values to determine the degree of deacetylation (GD). The morphology indicates the homogeneity of the structure and the surface. The X-ray diffraction shows the reduction of crystallinity of QNC, which corresponds to the amorphous structure thereof. The value of the zeta potential of the chitosan acetate (AQ) in acid media ( $\mathrm{pH} 4.43$ ) was $43.6 \mathrm{mV}$, while the value of QNC ( $\mathrm{pH} 7.3$ ) was $15.4 \mathrm{mV}$ due to its high polydispersity. The variation in particle size of samples, and AQ using QNC $0.450 \mathrm{uM}$ mesh filter, indicated the average particle size of 55.52 and $266.0 \mathrm{~nm}$, respectively.
\end{abstract}

Keywords: chitosan nanocrystalline, regenerative medicine, tissue engineering
Volume I Issue I - 2016

\author{
Pighinelli L,' Guimarães MF,' Becker CM,' \\ Zehetmeyer $\mathrm{G}^{2}$ Rasia MG, ${ }^{2}$ Corrêa DS,' Paz \\ RL,' Zannin BG,' Kmiec M,' Tedesco MF,' \\ Reis V,' Silva MM,' Feijó CT,' Feistel CC' \\ 'Lutheran University of Brazil (Biomatter Lab) \\ ${ }^{2}$ Instituto SENAI Institute of Innovation in Polymers Engineering
}

Correspondence: Pighinelli L, Lutheran University of Brazil (Biomatter Lab), Brazil, Email pighinelli@gmail.com

Received: September 02, 2016 | Published: September 21, 2016

\section{Introduction}

Biomaterials are defined as naturally occurring materials or made by man and are used directly as a supplement and/or substituent of the functions of the living human body tissues. Two important parameters that need to have a biomaterial are biocompatibility and biofunctionality. ${ }^{1-3}$

Polysaccharides are a class of materials that have generally been underutilized in the field of biomaterials. The recognition of the usefulness and potential of this class of materials, however, is growing and the biomaterials field to the polysaccharide base, is about to experience rapid growth. Three factors specifically contributed to this growing recognition of biomaterials polysaccharides base. The recent development of new synthesis techniques using biologically active oligosaccharides, which will allow to expand and explore new research in the area of tissue engineering and the associated, need to create new biomaterials and biocomposites with specific properties, controllable biological activity and biodegradability. ${ }^{4}$

Chitosan (poly ( $\beta$ - $(1,4)$-D-glucosamine) and its derivatives are characterized by their excellent biostimulant properties that facilitate the reconstruction and vascularization of damaged tissue, may also address the weaknesses of cellular components, wire forming little scarring. The cationic properties of chitosan are considered a linear polyelectrolyte with a high charge density. They can interact with negatively charged surfaces such anionic polysaccharides with proteins and based on numerous applications. ${ }^{5,6}$

Chitosan has a variety of physicochemical properties and biological properties, such as low toxicity and allergenicity. Biocompatibility and bioactivity make it a very attractive substance for various applications in fields, such as pharmaceutical and medicine. Its nontoxic, hydrophilic with extraordinary behaviour are great to create films. Chitosan is very suitable for medical applications, especially dressings and drug delivery system. ${ }^{6-9}$

In the treatment of wounds or burns, chitosan can be used in the form of coating films or membranes, colloidal solutions or sponges. Nowadays a large number of research groups have been dedicated to the production of new and better healing through synthesis and modification of biocompatible materials. Strategic chains are also focusing on wound repair acceleration through systematically designed dressings. In particular, efforts are pointing to the use of organic materials so that chitin and derivatives are capable of accelerating the repair process in molecular, cellular and systemic levels. ${ }^{10-14}$

Chemical derivations of chitosan provide to be good materials to promotion of new biological activity and modification of the mechanical properties. The primary amino groups in the molecule are reactive and provide mechanisms for lateral fixing of groups using a variety of reaction conditions. These additions in the side chain can disrupt the crystalline structure of the material and consequently increase the amorphous fraction. These changes produce a material with lower stiffness and often changed their solubility. Changes in chemical and biological properties depend on the nature of the side group. Furthermore, the characteristics of chitosan, such as cationic, hemostatic and insoluble at high $\mathrm{pH}$, can be completely reversed, which can make the anionic water-soluble molecule, and also presenting anticoagulants properties..$^{15-20}$

Chitosan and its derivatives are polymers with excellent properties 
to be used in regenerative medicine, as they ensure efficiency in healing processes. The biocompatibility, non-toxicity and antibacterial activity is excellent properties for development of new biomaterials, on the other hand, shows strong resource sustainability, originating from biomass, or to be in the food industry, which further reinforce potential and the applicability of these polymers in health area. ${ }^{15}$

The preparation of chitosan waste bark, for example, shrimp (Pandalus borealis), is economically viable, environmentally friendly due to the large amount of waste available now as a product or as waste from the food industry. ${ }^{7}$

This article aims to develop a new method of obtaining nanocrystalline chitosan, evaluate chemical, structural and morphological properties in order to explore the potential of this class of materials and the importance of investing in the development of a multi science and interdisciplinary with profitable translational opportunities to generate new products helping the management of public health more diversified range of new low-cost products.

\section{Materials and methods}

\section{Materials}

Chitosan with a degree of deacetylation of $95 \%$ and $12.4 \%$ moisture content, colour of yellow powder cream, density $0.31 \mathrm{~g} / \mathrm{ml}$, data provided by Polymer Science and Nutrition S/A (Fortress EC), acetic acid $99.7 \%$ pa (Dynamic) and sodium hydroxide (Sigma-Aldrish). All chemicals were used as received without further purification.

\section{Methods}

Synthesis of acetate $95 \%$ deacetylated chitosan: The used chitosan was dissolved in acetic acid and were prepared four subsequently solutions containing $1: 0.4 ; 2: 0.8 ; 3: 0.9$ to $2: 2$ polymer content and acetic acid respectively, as shown in Table 1 . The dissolution occurred under agitation for propeller mixer at room temperature for a period of 2 hours at a speed 1,000 rpm to obtain one homogeneous and transparent solution. Twenty-four hours after the dissolution, each solution was filtered and the samples placed in open form polystyrene containers Petry card type to its drying at room temperature.

Table I Chitosan acetate solutions at different concentrations of acetic acid and polymer content

\begin{tabular}{lll}
\hline Solution & $\begin{array}{l}\text { Acetic acid concentration } \\
(\%)\end{array}$ & $\begin{array}{l}\text { Polymer content } \\
(\%)\end{array}$ \\
\hline A & 0,4 & 1 \\
B & 0,8 & 2 \\
C & 0,9 & 3 \\
D & 2 & 2 \\
\hline
\end{tabular}

\section{Obtention method of nanocrystalline chitosan}

Synthesis of nanocrystalline chitosan from the chitosan acetate solution: The four solutions of chitosan acetate with about 2 liters, prepared above, with the following concentrations of $1: 0.4 ; 2: 0.8$; 3:0.9 to $2: 2$ polymer content and acetic acid respectively referred to as A-I, B-II, C- and D III-IV. These solutions were under constant stirring at a rotation of $1,000 \mathrm{rpm}$ by a propeller mixer at room temperature for 30 minutes, then was added amounts of glycerol as a plasticizer: $5 \mathrm{ml} ; 7.5 \mathrm{ml} ; 10 \mathrm{ml}$ and $10 \mathrm{ml}$ respectively, which are relating to $0.4 \%$ of polymer content. Then the respective solutions were added gradually sodium hydroxide $(\mathrm{NaOH})$ solution, with constant stirring, with the respective concentrations of acetic acid to obtain complete neutralization of the acid in question, as shown in Table 2. After standing for twenty- four hours packed under cooling at constant temperature of $5^{\circ} \mathrm{C}$, the solution was filtered and washed with Büncher funnel with three liters of distilled and deionized water to remove the salt, residual sodium acetate which was formed in the neutralization reaction of acetic acid with sodium hydroxide. The samples were placed in polystyrene containers open type Petry plate until its drying at room temperature.

Table 2 Chitosan acetate solutions at different concentrations, polymer content and amount of glycerin.

\begin{tabular}{lllll}
\hline Solution & $\begin{array}{l}\text { Acetic acid } \\
\text { Concentration } \\
(\%)\end{array}$ & $\begin{array}{l}\text { Polymer } \\
\text { content } \\
(\%)\end{array}$ & $\begin{array}{l}\text { Quantity } \\
\text { of } \\
\text { glicerina } \\
(\mathbf{m L})\end{array}$ & $\begin{array}{l}\begin{array}{l}\text { Solution } \\
\text { of } \\
\mathbf{N a}\end{array} \\
\mathbf{( \% )}\end{array}$ \\
\hline A - I & 0,4 & 1 & 0,5 & 0,4 \\
B-II & 0,8 & 2 & 0,75 & 0,8 \\
C-III & 0,9 & 3 & 10,00 & 0,9 \\
D - IV & 2 & 2 & 10,00 & 2 \\
\hline
\end{tabular}

Analytical methods for the characterization of chitosan acetate and nanocrystalline chitosan

Absorption Spectroscopy in the Infrared Region Fourier Transform - (FTIR - ATR): FTIR spectra in the infrared region were recorded on a Perkin Elmer model Spectrum One, the region in the spectral range $4000-650 \mathrm{~cm}^{-1}$, number 8 scans and resolution of $4 \mathrm{~cm}^{-1}$. The measurements were performed in Reflectance Total Attenuated mode.

Scanning Electron Microscopy with Chemical Analysis by Energy Dispersive (SEM-EDS): The morphology of the chitosan samples was analysed in an electron microscope digital scan-brand JEOL-JSM-6010LA model. To perform the analysis SEM -EDS part of the sample was bonded to the support (stub) with a tape of carbon and these were coated with a thin carbon layer by evaporation, to make them more conductive. It selected a region for evaluation by EDS. The images form obtained by detector Electrons Secondary (SEI), 15kV, under high vacuum, Working Distance: $10 \mathrm{~mm}$ Spot Size: 30

X-Ray Diffraction (XRD): The diffraction data X-ray were obtained using Rigaku X-Ray equipment Difractometer (XRD). Chitosan samples were analyzed by measurements of X-ray diffraction with copper tube $(\lambda=1.54 \AA)$, using voltage $40 \mathrm{kV}$ and $40 \mathrm{~mA}$ current. The measurements were performed in the range $3^{\circ}<2 \theta$ and graphite monochromator, normal incidence at room temperature. The results of the analysis were obtained by indexing the crystallographic forms.

Nuclear Magnetic Resonance Hydrogen (1H-NMR): The 1H-NMR spectra were obtained on a Varian Unity Plus $400 \mathrm{MHz}$ spectrometer In order to improve the resolution of the peaks the following conditions were setz: 16 scans accumulated pulse and the LB $0.30 \mathrm{~Hz}$ spectral width, and points was $5000 \mathrm{~Hz}$ and $64 \mathrm{~K}$, respectively. The spectra were calibrated from the signal due to HOD. Initially, a solution acidified $1 \%(\mathrm{v} / \mathrm{v})$ was prepared by adding $0.05 \mathrm{~mL}$ of concentrated $\mathrm{HCl} 4.95 \mathrm{~mL}$ of $\mathrm{D}_{2} \mathrm{O}$. About $20 \mathrm{mg}$ of sample were added to $5 \mathrm{ml}$ of this solution and maintained under constant agitation for 24 hours at 
room temperature. $\mathrm{HCl}$ was added to the solvent in sufficient quantity $\left(\mathrm{D}_{2} \mathrm{O} / \mathrm{HCl} 100: 1 \mathrm{v} / \mathrm{v}\right)$ to promote solubilizing chitosan (essential for the neutralized form of chitosan), and in order to displace interfering signals in the region examined to determine the level of acetylation. An aliquot of this viscous solution was placed in quartz tubes of $5 \mathrm{~mm}$ diameter. To reduce the interference of the solvent signal (HDO) with the sample peaks, the experiment was conducted at a temperature of $70^{\circ} \mathrm{C}$. NMR signals and integration of the peaks were assigned with the aid of MestReNova program.

Zeta Potential and particle size: The zeta potential and particle size of the chitosan acetate solution and nanocrystalline chitosan were measured using the ZETASIZER NANO ZS90 apparatus (Malvern Instruments).

\section{Results and discussion}

\section{Study spectroscopy in the infrared fourier transform spectroscopy (FTIR-ATR)}

The characteristic spectra in the infrared region of the precursor chitosan and the method of obtaining chitosan acetate salt (AQ) were confirmed by FTIR technique-TRS. That is illustrated in Figure 3. Spectra were observed in the presence of bands in the region of $3200 \mathrm{~cm}^{-1}$ relating to the stretching vibrations of the $\mathrm{OH}$ and $\mathrm{NH}$ chitosan and also with regard to water absorption, the band 2800$2880 \mathrm{~cm}^{-1}$ assigned to $\mathrm{CH}$ (symmetric) stretching the band in the region $1631 \mathrm{~cm}^{-1}$ corresponding to stretching $\mathrm{C}=\mathrm{O}$ of amide $\mathrm{I}$ characteristic of chitosan is not fully deacetylated and $1540 \mathrm{~cm}^{-1}$ band assigned to deformation $\mathrm{NH} 2$. The bands at $1150 \mathrm{~cm}^{-1}$ and $899 \mathrm{~cm}^{-1}$ refer to the chemical group COC (glucose- $\beta-1-4){ }^{21}$

Analysing the spectra of the infrared nanocrystalline chitosan region (QNC), it was observed the similarity to with chitosan acetate (AQ), varying only the intensities of the bands that are proportional to polymer concentration. This confirms that after the aggregation method macromolecule structure glucosamine and purification process shown in Figure 2, nanocrystalline chitosan shown with the main precursor of chitosan identifying peaks as illustrated in Figure 4.

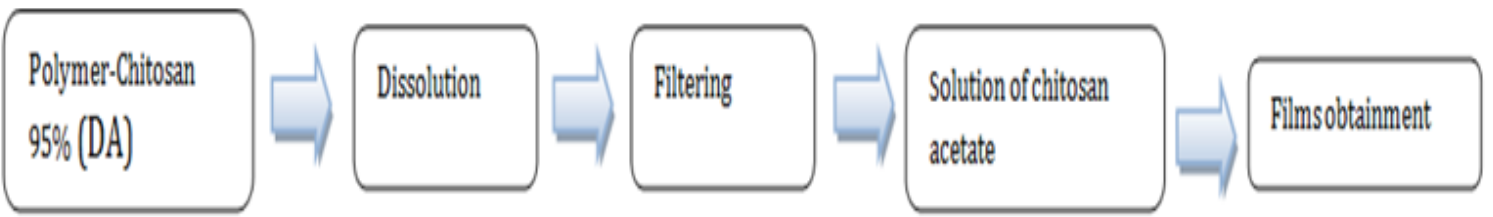

Figure I The dissolution method chitosan.

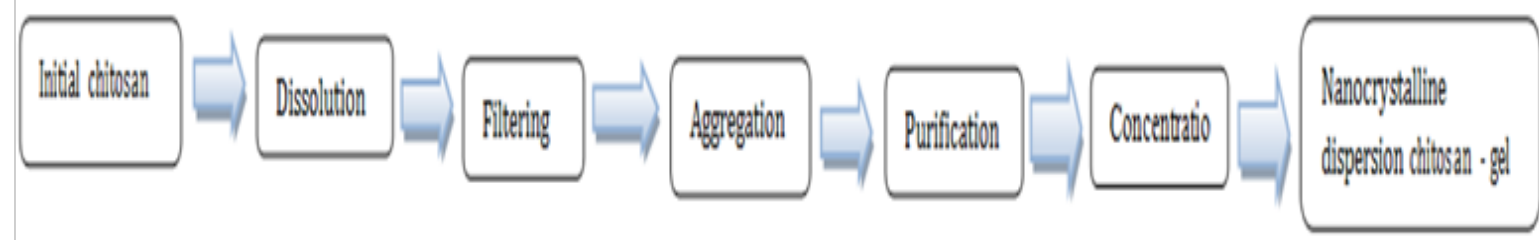

Figure $\mathbf{2}$ The production method is exemplified.

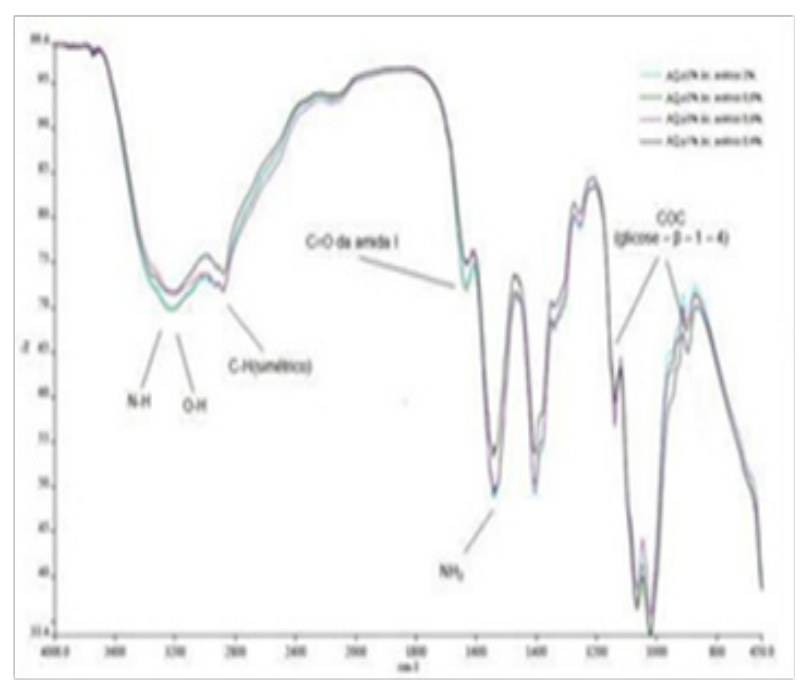

Figure 3 IR spectrum of chitosan in different concentrations.

\section{Morphology}

Morphology of the films of chitosan acetate: The technique of scanning electron microscopy was used in order to evaluate the morphology of the surfaces of samples of ethyl Chitosan. Figure 5 are observed in micrographs of the samples of the chitosan acetate films at different concentrations as shown in Table 1, a smooth, homogeneous and well dispersed, i.e. without formation of agglomerates, but with a texture characteristic (Figures 5A \& 5B). The sample obtained the best results in the morphology study to continue the studies was 1:0.4 related to polymer concentration and acetic acid respectively, and this sample illustrated in the figure below. Figure 5C illustrates the compositional range of the region where EDS analysis was done.

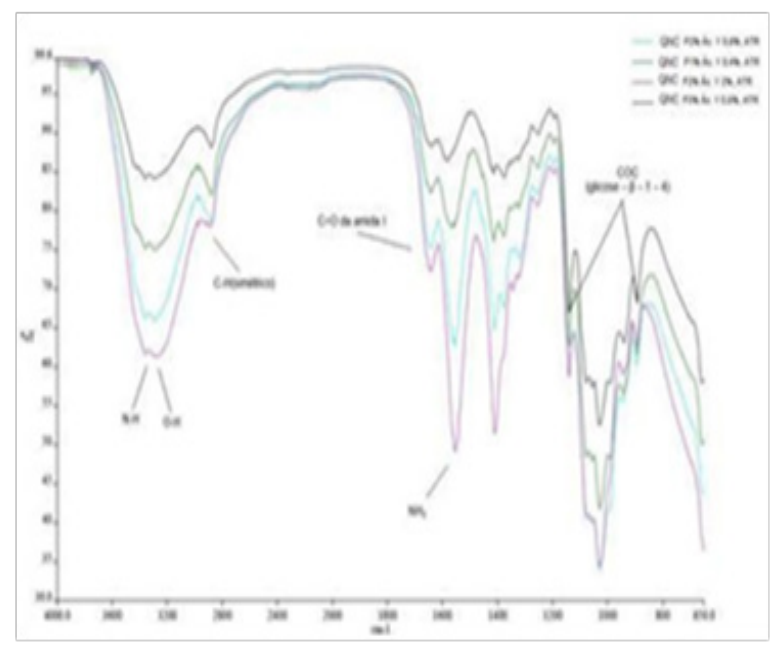

Figure 4 IR spectrum of nanocrystalline chitosan in different concentrations. 
The energy dispersive spectroscopy (EDS) was used to identify constituents of the sample and semi-quantitative results of the elements present in the chitosan acetate film 1:0.4, presented as in Figure $5 \mathrm{C}$ and Table 3.

Table 3 Results of semi-quantitative elements present in samples of dry chitosan acetate at room temperature obtained by the EDS. The traces in mass percent of the study sample 1:0.4 for the silicon and sodium suggest waste impurities arising from the process of obtaining initial chitosan used in this research. Carbon, Nitrogen and Oxygen confirm the organic and structural character of the polysaccharide confirmed by FTIR item 3.1.

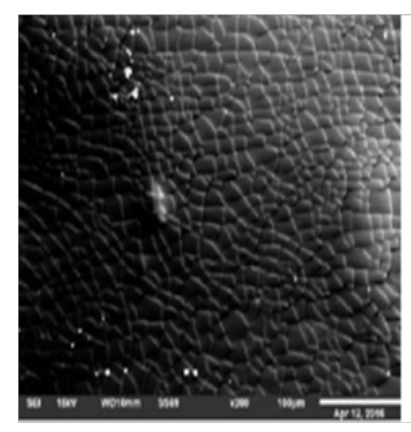

(A)

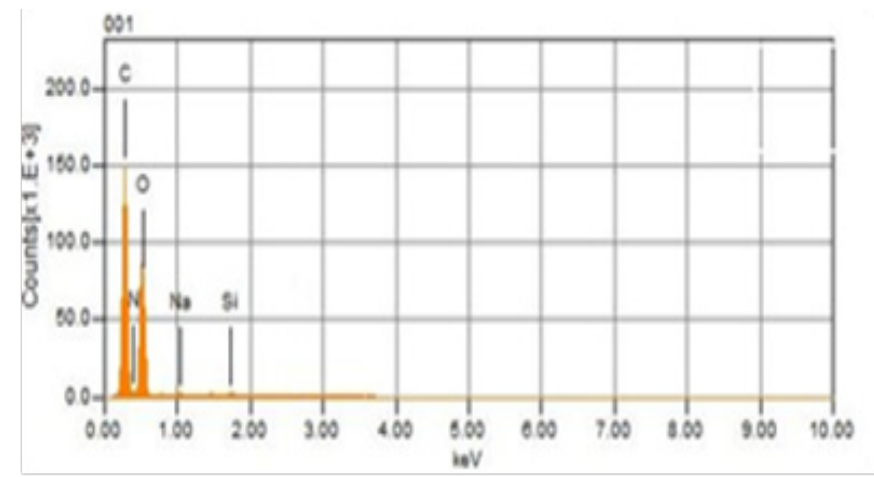

(C)

Figure 5 Images from the scanning electron microscope samples of chitosan acetate films, dried at room temperature (A and B) AQ I:0.4 in polymer content and acetic acid concentration with magnifying (A) 200 and (B) $x$ I.000. (C) the compositional spectrum of the region where it was made EDS analysis for the image with magnification 200x.

\section{Morphology of chitosan nanocrystalline}

As Figures $6 \mathrm{~A} \& 6 \mathrm{~B}$, there is a sample obtained by nanocrystalline Chitosan Chitosan acetate solution 1: 0.4 for polymer content and acetic acid respectively. From SEM micrographs, it was observed that samples of the same nanocrystalline hold chitosan chitosan acetate behaviour showing a homogeneous surface, easy to obtain films, but with a different texture of chitosan acetate films. The agglomerates appearance suggests a higher water retention also evidenced by FTIR with increased band $3200 \mathrm{~cm}^{-1}$ (Figure 4), this increase is related to the increased hydrophilicity of the polymer (amorphous part) due to dissolution of the macromolecule glucosamine and subsequent recrystallisation of the same. Figure $6 \mathrm{C}$ illustrates the constituents present in the chitosan sample nanocrystalline 1:0.4. The semiquantitative results of the elements present in the chitosan sample nanocrystalline 1:0.4 are shown according to Table 4.

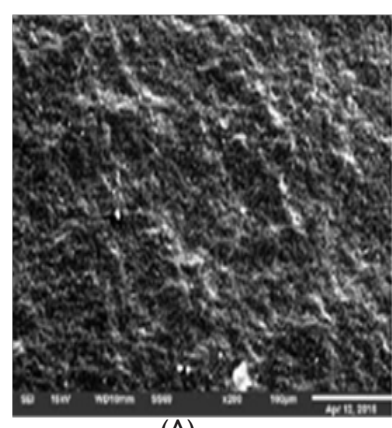

(A)

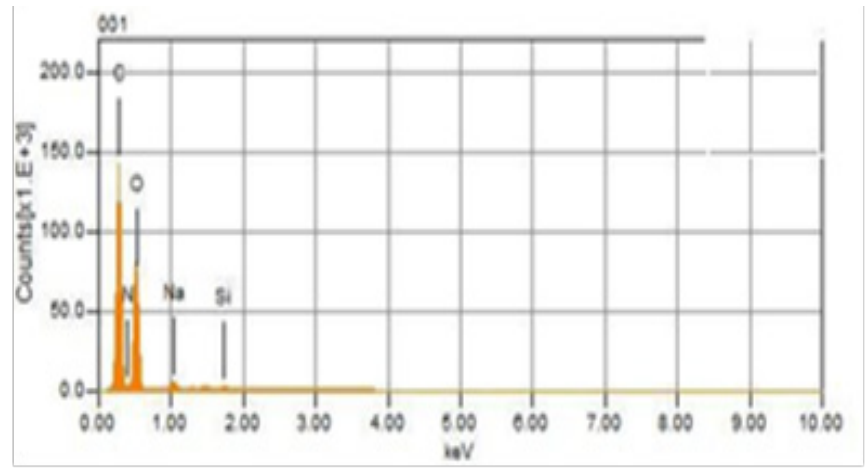

(C)

Figures 6 Images from the scanning electron microscope sample of chitosan nanocrystalline film (A and B) I:0.4 in polymer content and concentration of acetic acid, magnification (A) 200 and (B) 1000x. (C) The compositional spectrum of the region where it was made EDS analysis for the image with magnification 200x.

Regarding traits in percentage by mass of the sample in study 1:0.4 for the silicon and sodium, silicon remained without a significant increase, unlike the sodium concentration increased significantly attributed to the agglomeration process of macromolecule glucosamine using sodium hydroxide. The purification process for removal of residual sodium acetate was not effective, being necessary to wash longer and with a greater amount of distilled water. Carbon, Nitrogen and Oxygen confirm the organic and structural character of the polysaccharide confirmed by FTIR item 3.1.

Table 3 Results of semi-quantitative elements present in samples of dry chitosan acetate at room temperature obtained by the EDS

\begin{tabular}{ll}
\hline Chemical elements & AQ I:0,4 (\% massa) \\
\hline $\mathrm{C}$ & 52,72 \\
$\mathrm{~N}$ & 4,90 \\
$\mathrm{O}$ & $41,8 \mathrm{I}$ \\
$\mathrm{Na}$ & 0,20 \\
$\mathrm{Si}$ & $0,1 \mathrm{I}$ \\
\hline
\end{tabular}

\section{Diffractogram X-ray}

The use of X-ray diffraction also allows distinguishing clearly the starting precursor chitosan $(\mathrm{QP})$, chitosan acetate $(\mathrm{AQ})$ and its derivative chitosan the nanocrystalline (QNC). The diffract gram of commercial chitosan sample showed more intense and/or better peak, defined as that observed in the XRD patterns of chitosan after the reactions with acid and neutralization with sodium hydroxide (Figure 
7), which is attributed to the existence of crystalline domains larger and more in the case of commercial chitosan. According Samuels, ${ }^{22}$ the peaks at $10^{\circ}$ and $20^{\circ}$ are characteristic of crystallinity of the chitosan membrane. Samples AQ 1:0.4 (broader band) have much less intense signals and are typical of amorphous chitosan due to the dissolution of the macromolecule of glucosamine by acetic acid. The lack of land to be attributed to the presence of positive charges (due to protonation of the amino groups) in the chain of samples and their respective counter ions (Figure 7), however the QNC samples show that they are similar in crystallinity. Suggesting a reduction of the crystal size, consequently the crystalline region and the amorphous region increases significantly, resulting in a structural change of the leaving polysaccharide polymer more reactive and less structural characteristics.

Table 4 semi-quantitative results of the elements present in the samples analyzed nanocrystalline chitosan, dried at room temperature obtained by the EDS

\begin{tabular}{ll}
\hline Chemical Elements & QNC I:0,4 (\% massa) \\
\hline $\mathrm{C}$ & $53,0 \mathrm{I}$ \\
$\mathrm{N}$ & 4,56 \\
$\mathrm{O}$ & $4 \mathrm{I}, 4 \mathrm{I}$ \\
$\mathrm{Na}$ & $0,9 \mathrm{I}$ \\
$\mathrm{Si}$ & $0,1 \mathrm{I}$ \\
\hline
\end{tabular}

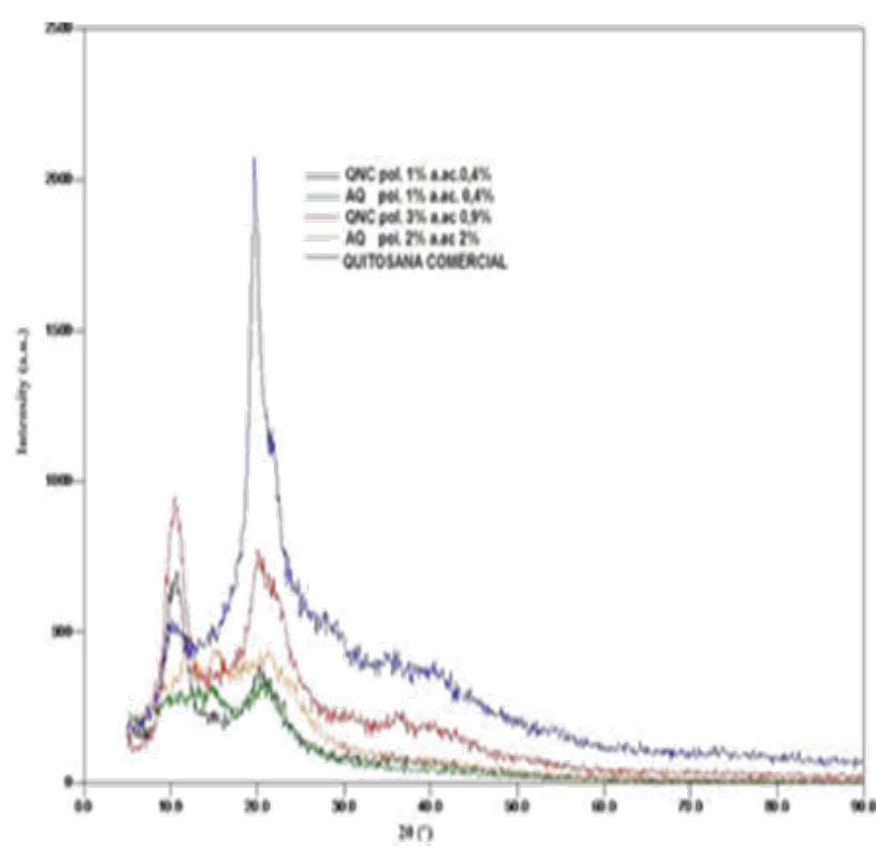

Figure 7 XRD pattern of the precursor chitosan acetate AQ (A) I:0.4 and (D) $2: 2 \%$ polymer concentration and acid concentration and the QNC (AI) I:0.4 and (C-III) 3:0.9\% polymer concentration and acetic acid concentration.

\section{Nuclear magnetic resonance of hydrogen (I H-NMR)}

The degree of deacetylation (GD) is considered one of the main parameters in the characterization of chitosan. It is defined as the number of free amine groups to the number of groups of the polymer chain. The assignment of the signal observed in the spectra of Figure 8 corresponds to the signals, between 3 and $4 \mathrm{ppm}$ of the hydrogens attached to carbons 2-6 and glycosaminoglycans ring. The singlet at $1.96 \mathrm{ppm}$ region corresponds to the hydrogen from the methyl acetamido group. The reduction of AQ GD 1: 0.4 refers to the dissolution of the macromolecule of glucosamine with addition of acetic acid, favouring the creation of new acetyl groups, as shown in Figure 8A. The increased GD QNC 1:0.4 recrystallization is related to the glucosamine molecule with addition of sodium hydroxide, favouring the creation of new amino groups, due to sodium ions bind more easily to the acetyl group, freeing again free amine groups as shown in Figure 8B. The GD AQ and QNC determined from the $1 \mathrm{H}$ NMR spectrum of chitosan was 64 and $84 \%$, respectively. That is, $64 \%$ of the monomers of the AQ are deacetylated and $36 \%$ are acetylated (Figure 3). In QNC, only 16\% of the monomers were acetylated.

According to the technical information provided by enterprise Polymer, commercial chitosan used in this work has a GD of approximately $95 \%$. The determination of NMR GD is recommended for samples with high chitosan deacetylation degree and has been the method most used in these cases. ${ }^{23-25}$

\section{Zeta Potential and particle size}

The particle size and zeta potential analyses were performed in two different ways. The analyses of the samples chitosan acetate (AQ) 2:0.8 and nanocrystalline chitosan (QNC) 2:2 were made with and without the use of filters, as shown in Figure 9 and Table 5. These samples were used due to high content of polymer and high acetic acid content to know the influences of these two parameters in the outcome. Figure 9A \& 9B shows the distribution of the particle size of the chitosan acetate (AQ) and nanocrystalline chitosan (QNC), without a filter, indicating the average particle size of $490.4 \mathrm{~nm}$ and 142.5, respectively. This shows that QNC has a more reactive, hydrophilic and more susceptible to particulate agglomeration. Figure 9C \& 9D illustrates the variation in particle size of the samples, and AQ QNC using mesh $0.450 \mathrm{uM}$ filters, indicating the average particle size of $266.0 \mathrm{~nm}$ and 55.52, respectively, showing the decreased polydispersity QNC the sample.

The high reactivity of QNC induces agglomeration of the chitosan nanoparticles which reflect in increased polydispersity, which is a characteristic of most amorphous polymers character. ${ }^{7}$ Table 5 illustrates the difference in stability between the two solutions. It is observed that due to the high polydispersity related to high variation of molecules of various sizes and molecular weights, it was not possible to measure zeta potential of AQ and QNC solutions without the use of filters. The use of mesh $0.450 \mathrm{uM}$ filter intended to reduce the polydispersity of the solutions to reduce the variation in molecular size, which is illustrated in Figure 9 and Table 5.

The measured zeta potential of the medium conducted in order to study the stability of the dispersion and the chitosan acetate solutions compared to the nanocrystalline chitosan. It is observed that the value of the zeta potential of AQ in acid medium ( $\mathrm{pH} 4.43$ ) is $43.6 \mathrm{mV}$, due to the amino groups are protonated $(\mathrm{NH} 3+)$. According to Figueiredo ${ }^{26}$ when the $\mathrm{pH}$ is at the $\mathrm{pKa}$ of chitosan ( 6) amine groups start to deprotonate (NH2) and zeta potential starts to decrease, which means that the load of chitosan tends to be nil. Therefore, the value of the zeta potential of $\mathrm{QNC}(\mathrm{pH} 7.3)$ was $15.4 \mathrm{mV}$, i.e nanocrystalline chitosan behaviour resembles that of the precursor chitosan. 


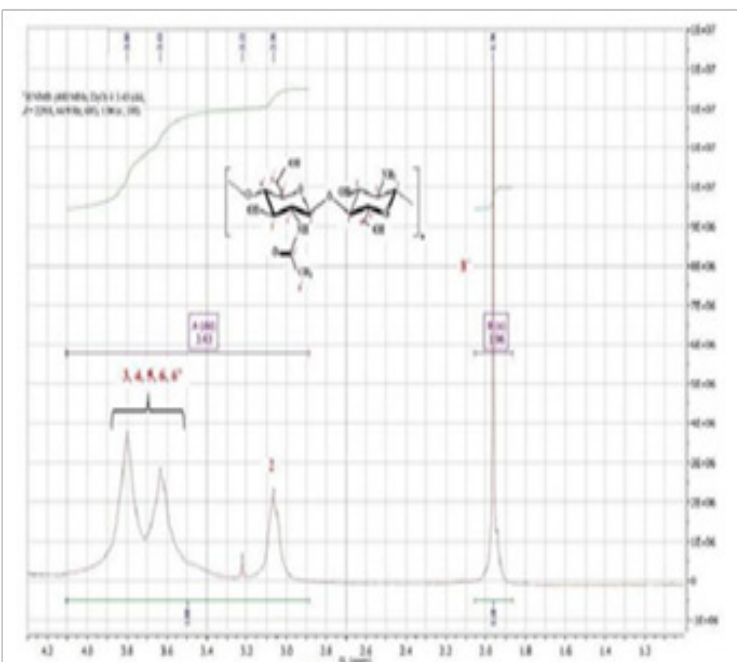

(A)

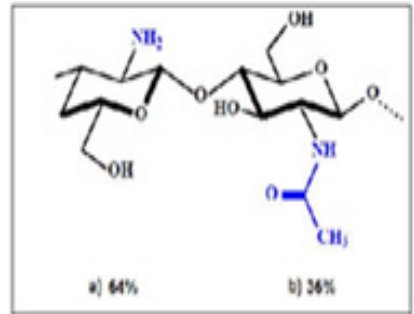

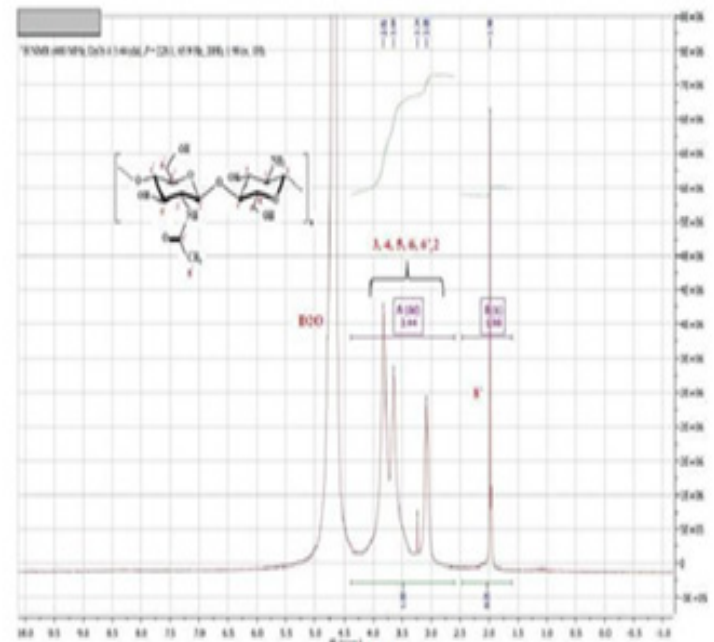

(B)

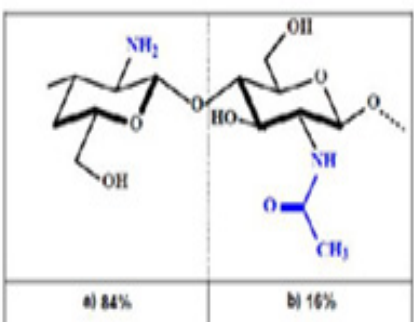

Figure $8 \mathrm{HI}$ NMR Spectrum AQ and QNC in D2O/HCl in a concentration of $5 \mathrm{mg} / \mathrm{ml}$. The hydrogens are represented by numbers according to the carbon position which they are attached to deacetylated and acetylated monomer monomers. Often repetitive units occur in ethyl Chitosan, in percentage terms: (A) acetylated units; (B) deacetylated units.

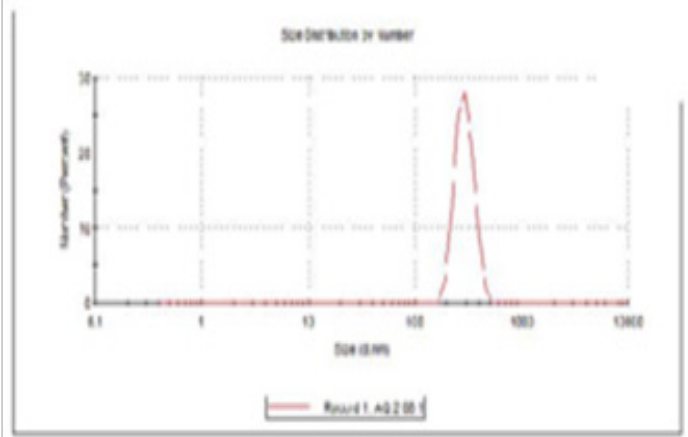

(A)

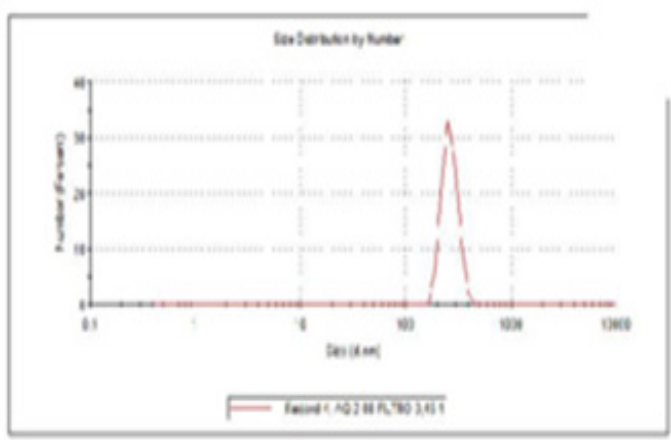

(C)

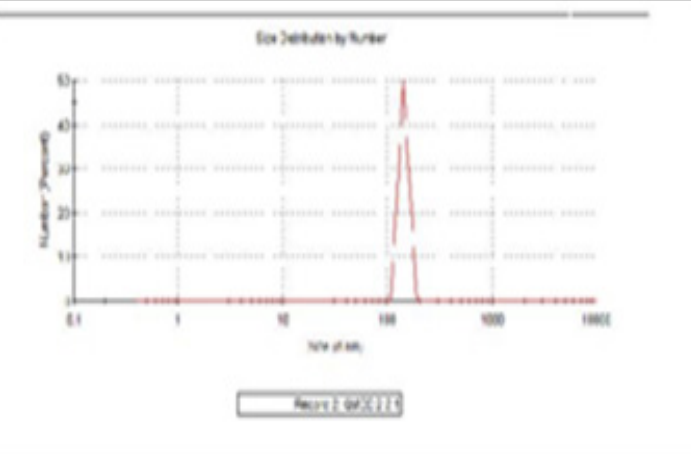

(B)

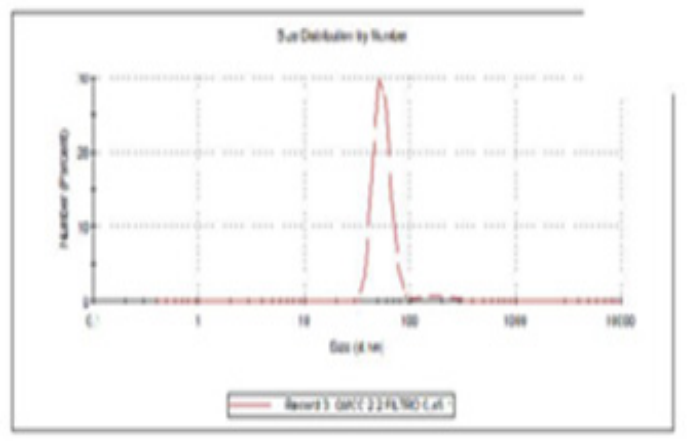

(D)

Figure 9 particle size distribution: (A) AQ 2:0.8 unfiltered, (B) QNC 2:2 without filter, (C) AQ 2:0.8 to 0.450uM filter and (C) QNC 2:2 with filter 0,450 micrometers. 
Table 5 shows that the use of QNC obtaining method got a $55.52 \mathrm{~nm}$ particle size

\begin{tabular}{llll}
\hline Samples & Particle size $(\mathbf{n m})$ & Number $(\%)$ & Standard deviation (nm) \\
\hline AQ 2:0,8 & 293,6 & 100 & 57,32 \\
QNC 2:2 & 142,5 & 100 & 14,79 \\
AQ 2:0,8 with filter 0,450 & 266,0 & 100 & 45,01 \\
QNC 2:2 with filter 0,450 & 55,52 & 96,3 & 10,34 \\
\hline
\end{tabular}

\section{Conclusion}

This research was developed a new method for obtaining nanocrystalline chitosan, chitosan acetate derived. The FTIR results show the same chemical structure of the precursor of chitosan acetate and chitosan nanoparticulate not form observed changes in chemical structure and secondary products from the method of obtaining the nanocrystalline chitosan.

The study of morphology and EDS showed homogeneity on the surface of the obtained films and silicon and sodium traces in samples of chitosan acetate and increase in sodium traces on nanocrystalline chitosan due to agglomeration of the macromolecule glucosamine process. The analysis of X-ray diffraction showed the characteristic peaks of crystallinity precursor of chitosan, a decrease in the crystallinity of the chitosan acetate due to the dissolution of the macromolecule of glucosamine, increasing its amorphous character. This effect was more pronounced in nanocrystalline chitosan decreasing the size of the crystal, micro to nano also observed by particle size analysis, thus increasing its amorphous character, hydrophilic and consequently the reactivity of the polymer.

The magnetic resonance analysis also illustrates this structural change, adding to the variation of the index deacetylation, chitosan acetate both as the nanocrystalline chitosan. In the chitosan acetate was reduced deacetylation of the index, which indicates that the polymer dissolution process with acetic acid there was a decrease of free amino groups that were reacetilados by adding acetic acid. It was possible to observe an opposite behavior recrystallization macromolecule glucosamine in the method for obtaining nanocrystalline chitosan (agglomeration process). Addition of sodium hydroxide caused a increase in free amino groups to form sodium acetate, thus increasing the deacetylation index.

The value of the zeta potential of the AQ 2:0.8 in acid medium (pH 4.43 ) was $43.6 \mathrm{mV}$. While the value of QNC 2:2 (pH 7.3) was $15.4 \mathrm{mV}$. Thus, the behavior of nanocrystalline chitosan did not become stable due to the high polydispersity. The variation of the particle size of the samples AQ 2:0.8 and QNC 2:2 using 0.450uM mesh filter, indicated the average particle size of 55.52 and $266.0 \mathrm{~nm}$, respectively.

The nanocrystalline chitosan prepared by this method remained the same structure of the precursor chitosan therefore indicates to have the same properties of the initial chitosan, with a large increase in its hydrophilic character and extraordinary behaviour for direct training films and creating a particulate nano structure. This derivative of chitosan has a great potential for medical and pharmaceutical applications, creating a generation of biomaterials nano particles and to foster the creation of new complexes for regenerative medicine and tissue engineering.

\section{Acknowledgements}

Analysis of the spectra in the infrared (FTIR-ATR) and scanning electron microscopy with energy dispersive chemical analysis (SEM-EDS) were performed using the equipment provided by SENAI Institute for Innovation in Polymer Engineering. The X-ray diffraction and nuclear magnetic resonance of hydrogen (1H-NMR) were performed using the equipment provided by the Research Center for Product and Development (CEPPED) of the Lutheran University of Brazil (ULBRA). The zeta potential and particle size analysis (ZETASIZER NANO) were performed using the equipment provided by the Faculty of Pharmacy, Department of Production and Drug Control in the Federal University of Rio Grande do Sul (UFRGS).

\section{Conflict of interest}

The author declares no conflict of interest.

\section{References}

1. Misiek DJ, Kent JM, Carr RF. Soft tissue responses to hydroxyapatite particles of different shapes. J Oral Maxillofac Surg. 1984;42(3):150 160.

2. Muzzarelli C, Muzzarelli RAA. Natural and artificial chitosan-inorganic composites. Journal of Inorganic Biochemistry. 2002;92(2):89-94.

3. Oktay Y. Preparation and characterization of chitosan/calcium phosphate based composite biomaterials, Master of Science Dissertation. Izmir, Turkey: Izmir Institute of Technology; 2004.

4. Francis Suh JK, Howard WT Matthew. Application of chitosan-based polysaccharide biomaterials in cartilage tissue engineering: a review. Biomaterials. 2000;21(24):2589-2598

5. Rinaudo M. Chitin and chitosan: properties and applications. Progress in Polymer Sciencei. 2006;31(7):603-632.

6. Kucharska M, Niekraszewicz A, Wisniewska Wrona M, et al. Dressing Sponges Made of Chitosan and Chitosan-Alginate Fibrids. Progress on Chemistry and Application of Chitin and Its Derivatives, Vol. IX. PTChit; 2003. p. 69-72.

7. Pighinelli Luciano, Kucharska Magdalena, Wawro Dariuz. Preparation of Microcrystalline chitosan: (MCCh0/tricalcium phosphate complex with Hydroxiapatite in sponge and fibre from for hard tissue regeneration. 2012. 19 p.

8. Muzzarelli RAA. Chitosan composites with inorganics, morphogenetic proteins and stem cells, for bone regeneration. Carbohydrate Polymers. 2011;83(4):1433-1445.

9. MNVR Kumar. A review of chitin and chitosan applications. Reactive \& Functional Polymers. 2000;46(1):1-27.

10. Qiao xia LI, Bao zhen Song, et al. Electrolytic conductivity behaviors and solution conformations of chitosan in different acid solutions. Carbohydrate Polymers. 2006;63(2):272-282. 
11. Mohy Eldin M, Soliman EA. Antibacterial activity of chitosan chemically modified with new technique. Trends Biomater Artif Organs. 2008;22(3):125-137.

12. Jianyun Wang, Dongming Zhang, Fei Liu, et al. Structure and properties of chitosan derivatives modified calcium polyphosphate scaffolds. Polymer Degradation and Stability. 2010;95(7):1205-1210.

13. Juan Peña, Isabel Izquierdo Barba, Alvaro Martínez, et al. New method to obtain chitosan/apatite materials at room temperature. Solid State Sciences. 2006;8(5):513-519.

14. Green S, Roldo M, Douroumis D, et al. Chitosan derivatives alter release profiles of model compounds from calcium phosphate implants. Carbohydr Res. 2009;344(7):901-907.

15. Melina Hamdine, Marie Claude Heuzey, et al. Effect of organic and inorganic acids on concentrated chitosan solutions and gels. Int J Biol Macromol. 2005;37(3):134-142.

16. Harish Prashanth KV, Tharanathan RN. Chitin/chitosan: modifications and their unlimited application potential-an overview. Trends in Food Science \& Technology. 2007;18(3):117-131.

17. Barbosa MA, PL Granja, CC Barrias, et al. Polysaccharides as scaffolds for bone regeneration. ITBM-RBM. 2005;26(3):212-217.

18. Skrtic D, JM Antonucci, ED Eanes. Amorphous calcium phosphate based bioactive polymer composites for mineralized tissue regeneration. $J$ Res Natl Inst Stand Technol. 2003;108(3):167-182.

19. Marino Lavorgna, Filomena Piscitelli, Pasqualina Mangiacapra, et al Study of the combined effect of both clay and glycerol plasticizer on the properties of chitosan films. Carbohydrate Polymers. 2010;82(2):291298.

20. Henryk Pospieszny, Wojciech Folkman. Factors modifying a biological activity of chitin derivatives. Ed. Progress on Chemistry and Application of Chitin and its Derivatives. PTChit. 2004;X:07-12.

21. Costa Jr E, Manshur HS. Preparação e caracterização de blendas de quitosana/poli(álcool vinílico) reticuladas quimicamente com glutaraldeído paraaplicação em engenharia de tecidos. Química Nova. 2008;31(6):1460-1466.

22. Wasina Thakhiew, Sakamon Devahastin, Somchart Soponronnarit. Effects of drying methods and plasticizer concentration on some physical and mechanical properties of edible chitosan films. Journal of Food Engineering. 2010;99(2):216-224.
23. Hirai A, Odani, H Nakajima A. Determination of degree of deacetylation of chitosan by ${ }^{1} \mathrm{H}$ NMR spectroscopy. Polymer Bulletin. 1991;26(1):8794.

24. Iamazaki E, Douglas de Britto, Carla C Schmitt, et al. Preparation of substituted ionic carbohydrate polymers and their interactions with ionic surfactants. Colloid and Polymer Science. 2004;283(1):33-40.

25. Lavertu M, Z Xia, AN Serreqi, et al. A validated 1H NMR method for the determination of the degree of deacetylation of chitosan. Journal of Pharmaceutical and Biomedical Analysis. 2003;32(6):1149-1158.

26. Figueiredo, Juliana Sá Leal. Síntese e caracterização de copolímeros de polietilenoglicol monometil éter em quitosana cationizada para futuras aplicações em biotecnologia, tese doutorado-Araraquara: [s.n]; 2014.

27. Henryk Pospieszny, Wojciech Folkman. Factors modifying a biological activity of chitin derivatives. Ed. Progress on chemistry and application of chitin and its derivatives. PTChit. 2004;X:07-12.

28. Costa ES, Manshur HS. Preparação e caracterização de blendas de quitosana/poli(álcool vinílico) reticuladas quimicamente com glutaraldeído para aplicação em engenharia de tecidos. Química Nova. 2008;31(6):1460-1466.

29. Wasina Thakhiew, Sakamon Devahastin, Somchart Soponronnarit. Effects of drying methods and plasticizer concentration on some physical and mechanical properties of edible chitosan films. Journal of Food Engineering. 2010;99(2):216-224.

30. HIRAI A, Odani H, NAkajima A. Determination of degree of deacetylation of chitosan by $1 \mathrm{H}$ NMR spectroscopy. Polymer Bulletin. 1991;26(1):87-94

31. Iamazaki E, Iamazaki, Douglas de Britto et al. Preparation of substituted ionic carbohydrate polymers and their interactions with ionic surfactants. Colloid and Polymer Science. 2004;283(1):33-40.

32. Lavertu M, Xia Z, Serreqi AN, et al. A validated 1H NMR method for the determination of the degree of deacetylation of chitosan. Journal of Pharmaceutical and Biomedical Analysis. 2003;32(6):1149-1158.

33. Figueiredo, Juliana Sá Leal. Síntese e caracterização de copolímeros de polietilenoglicol monometil éter em quitosana cationizada para futuras aplicações em biotecnologia. Tese doutorado-Araraquara: [s.n]; 2014. 